www.annualreviews.org Brown Algal Model Organisms

\title{
Brown Algal Model Organisms
}

\author{
Susana M. Coelho and J. Mark Cock
}

Laboratory of Integrative Biology of Marine Models (LBI2M), Station Biologique de Roscoff (SBR), CNRS, Sorbonne Université, 29680 Roscoff, France; email: coelho@ sb-roscoff.fr

Keywords. brown algae, life cycle, sex determination, multicellularity

\begin{abstract}
Model organisms are extensively used in research as accessible and convenient systems to study a particular area or question in biology. Traditionally, only a limited number of organisms have been studied in detail, but modern genomic tools are enabling researchers to extend beyond the set of classical model organisms to include novel species from less well-studied phylogenetic groups. This review focuses on model species for an important group of multicellular organisms, the brown algae. The development of genetic and genomic tools for the filamentous brown alga Ectocarpus has led to it emerging as a general model system for this group, but additional models, such as Fucus or Dictyota dichotoma, remain of interest for specific biological questions. In addition, Saccharina japonica has emerged as a model system to directly address applied questions related to algal aquaculture. We discuss the past, present, and future of brown algal model organisms in relation to the opportunities and challenges in brown algal research.
\end{abstract}

\section{INTRODUCTION}

Brown algae (phaeophytes) belong to the stramenopiles (or heterokonts), a eukaryotic supergroup that is phylogenetically distinct not only from the land plant lineage, but also from the red algae and the opisthokonts (fungi and animals) (Figure 1). Brown algae have been evolving independently from plants and animals for more than a billion years, and as a result of this independent evolutionary history, they exhibit many novel features that make them highly interesting targets, for example, for the discovery of new biomolecules (느) or as sustainable biofuel resources $(\underline{72}, \underline{127})$. 


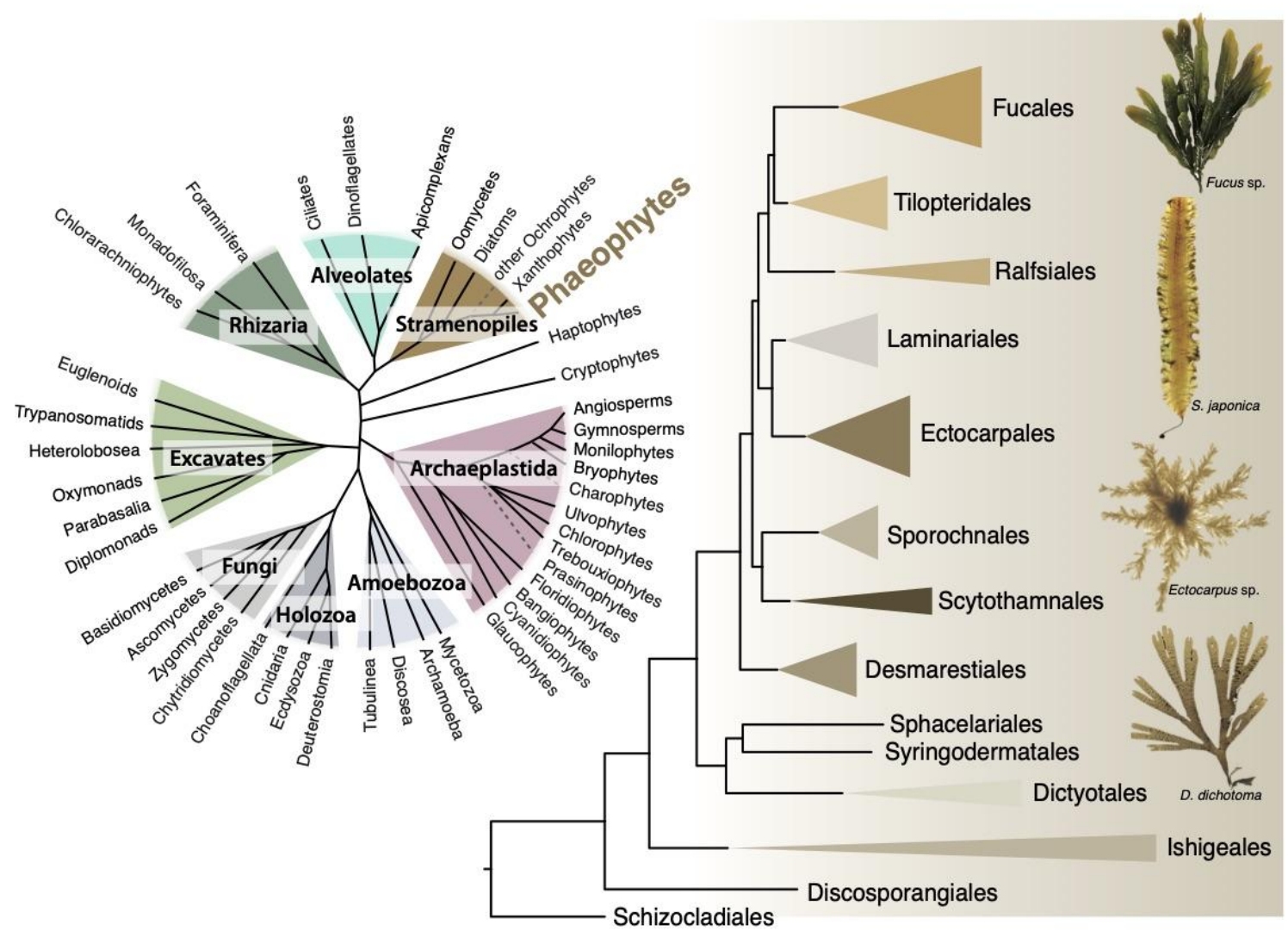


Figure 1 Phylogeny of the brown algae and sexual system diversity. Position of the brown algae (phaeophytes) within the eukaryotic tree of life (left panel) and a schematic tree of the class Phaeophyceae (right panel). Fucus sp., Saccharina japonica, Ectocarpus sp., and Dictyota dichotoma belong to the orders Fucales, Laminariales, Ectocarpales and Dictyotales, respectively. The cladogram of eukaryotes is adapted from Reference $\underline{36}$. 


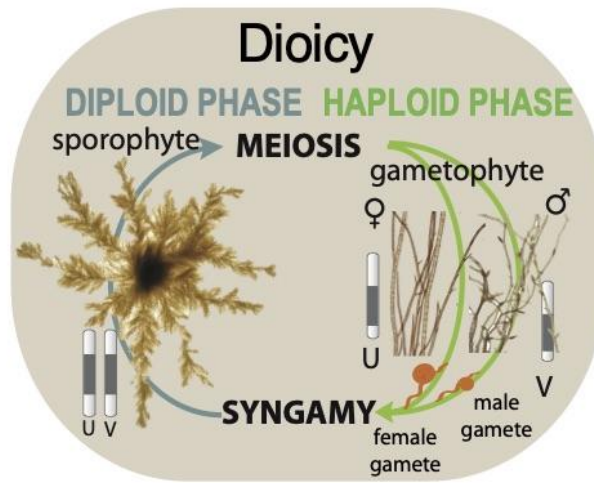

e.g. Ectocarpus sp.

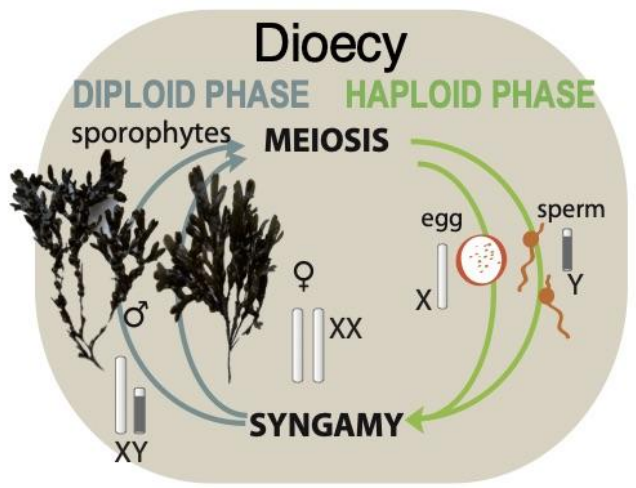

e.g. Fucus vesiculosus
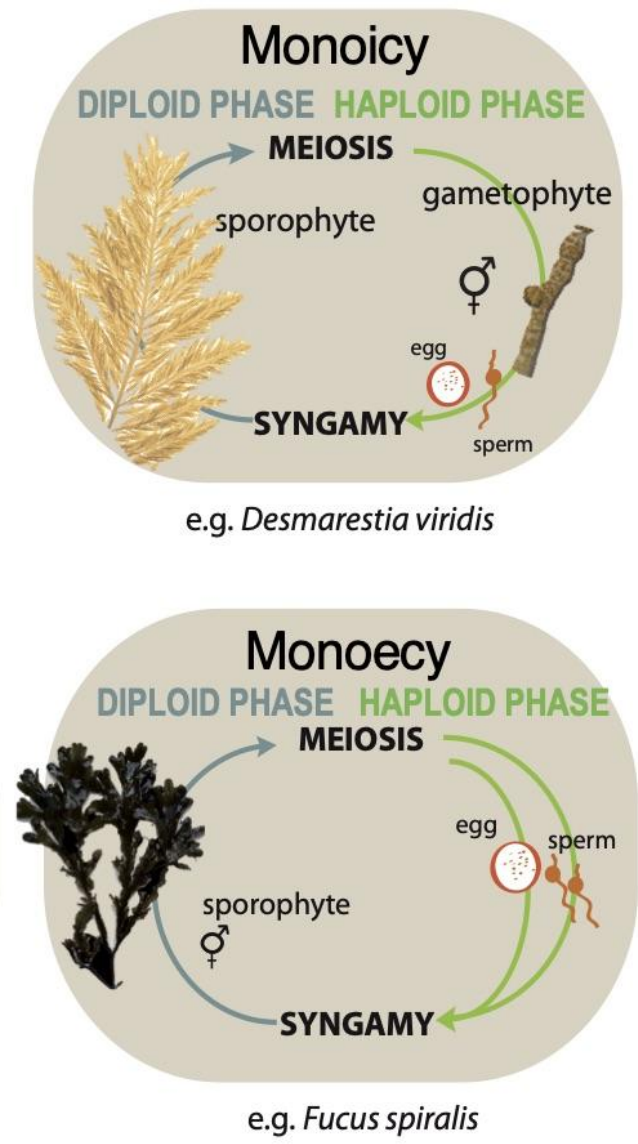
Figure 2 Four example species illustrating the diversity of sexual systems in the brown algae, which include both haploid (dioicy, monoicy) and diploid (dioecy, monoecy) phase sex determination, each associated with either cosexuality (monoicy, monoecy) or separate sexes (dioicy, dioecy). Bars represent sex chromosomes with the SDR in grey and the PAR in white. Fucus vesiculosus is indicated as having an XY sex chromosome system but could equally have a ZW system. Abbreviations: PAR, pseudoautosomal region; SDR, sex-determining region.

On a more fundamental level, the brown algae are one of only five eukaryotic lineages to have independently evolved complex multicellularity ( $\underline{32})$, which they express through a broad variety of morphologies ranging from uniseriate branched filaments (e.g., Ectocarpus sp.) to complex parenchymatous thalli (i.e., consisting of three-dimensional tissues derived from multidirectional cell divisions) with multiple cell types (e.g., Laminariales) ( $\underline{16})$. They also present a fascinating diversity of types of sexual system and reproductive mode (Figure 2). Note that the large diversity of developmental forms within this group has emerged within a relatively short period of evolutionary time [(less than $250 \mathrm{MY},(\underline{74})]$, compared with plant and animal lineages.

One consequence of the independent emergence of complex multicellularity in brown algae compared with animals and plants is that model systems from these latter two lineages are of limited relevance for understanding developmental processes in the brown algae. Therefore, it has been important to establish brown algal species as model organisms to study this lineage (Figures 1 and 2). These model systems have included the fucoids, which have been used for decades for cell biology approaches, and, more recently, Ectocarpus sp., which are currently being used to address a range of biological questions of broad relevance at the molecular and genetic levels. In the following sections, we describe both established and emerging brown algal model species, the opportunities and challenges associated with working with these organisms, and the outlook for the future. Note that this review focuses on laboratory model organisms and does not cover the use of selected brown algal species to address ecological questions. 


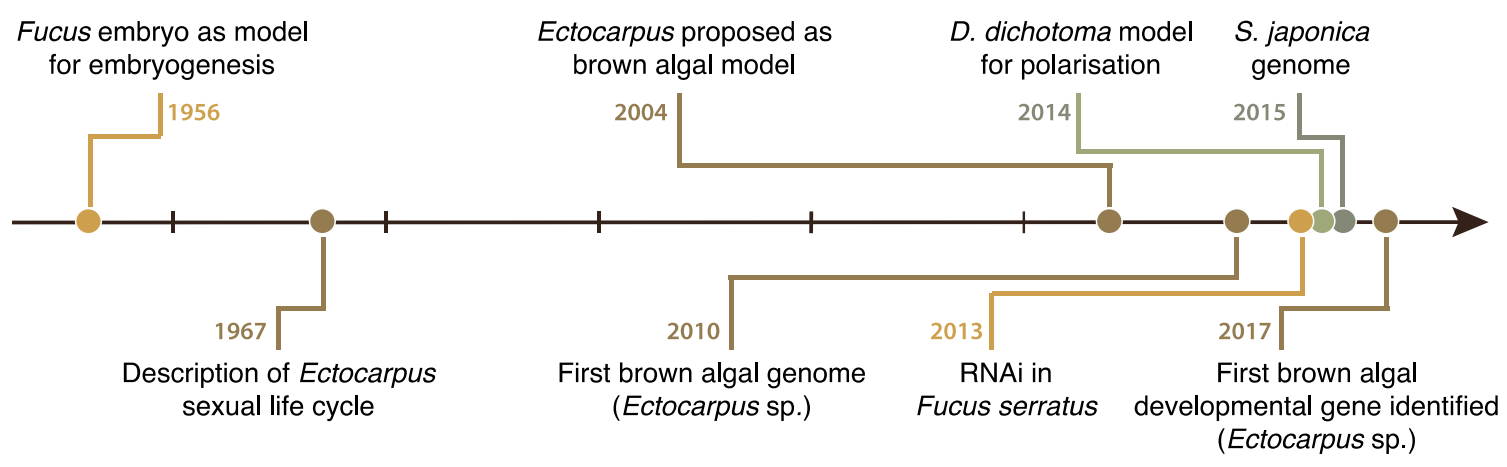

Figure 3 Timeline showing major landmarks in the emergence of the brown algal model species discussed in this review. Fucus is a model for cell biology and has been used to study early embryogenesis since the nineteen fifties. In 2013 RNAi was developed for Fucus serratus, opening up the possibility of investigating gene function during early development in this species. $D$. dichotoma has emerged more recently (2014) as an alternative model for early development studies. The advantage of $D$. dichotoma compared to Fucus is principally that strains can be maintained in culture and complete their life cycle under laboratory conditions. Early research using Ectocarpus as a model focused on characterisation of its life cycle, pheromone-based gamete attraction and infection by pathogens, particularly viruses. The availability of a complete genome sequence for Ectocarpus, together with genetic and genomic tools, has allowed the identification of key genes and genomic regions involved in life cycle regulation, development and sex determination. The sequence of the genome of the kelp Saccharina japonica was published in 2015, and this species being increasingly being used as a model system to directly address applied questions related to algal aquaculture. Abbreviation: RNAi, RNA interference.

\section{FUCOID ALGAE}

\section{Fucoid Zygotes and the Establishment of Zygotic Polarity}

Fucales (fucoid algae) are a brown algal order (i.e., within the class Phaeophyceae) that includes abundant and ecologically important organisms found on the upper intertidal shores of temperate oceans. Large egg cells are released into the seawater along with sperm, and fertilization and embryo development occur in the seawater, free from direct maternal influences. The zygotes divide asymmetrically to produce a small rhizoidal cell and a large apical cell. The rhizoidal cell gives rise to the holdfast, which anchors the alga to the rocky substratum, whereas the apical cell forms the stipe and fronds. 
Zygotes of fucoid brown algae, such as Fucus serratus or Fucus vesiculosus (Figures 1 and 2), have long served as models for understanding cell polarisation and embryonic asymmetric cell division (26). Fucoids were chosen as models to study these processes largely because of the ease with which gametes and zygotes can be obtained, and their suitability for cellular imaging studies and microinjection, coupled with the ability to carry out biochemical analyses of large numbers of synchronously developing zygotes.

Fucoid eggs possess no intrinsic polarity and no cell wall. After fertilisation, zygotes synthesize a cell wall within minutes and become polarised in response to external vectors, most frequently unilateral light. Photopolarisation and germination are followed by the asymmetric division of the zygote, with subsequent divisions occurring in a highly ordered, spatial, and temporal pattern $(\underline{17}, \underline{26}, \underline{61}, \underline{68})$.

Cell biological and biochemical studies using fucoid zygotes have provided important information about the cellular mechanisms involved in polarity acquisition and polarity axis fixation (e.g., $\underline{15}, \underline{21}, \underline{25}, \underline{113}$ ). Photopolarisation occurs in response to photoreceptor activation at the plasma membrane ( $\underline{71})$ and is associated with enhanced redox transport at the cell surface on the side of the zygote facing away from the light source (13). A light-sensitive redox transport process was suggested to be one of the earliest components of the signal transduction chain leading to photopolarisation (13). An alternative model proposed that the first asymmetry established during photopolarisation is spatial variation in the level of cyclic guanosine monophosphate (GMP) in response to a light gradient $(\underline{121}, \underline{122})$. Elevated cyclic GMP on the side of the zygote facing the light source would result in depolymerisation of actin in that region, with actin becoming increasingly polymerised towards the rhizoid pole facing away from the direction of the light direction ( $\underline{60})$. Accordingly, a cortical actin patch is detected at the future rhizoid pole in response to a polarizing light vector within $3 \mathrm{~h}$ of fertilization, corresponding to the early stages of photopolarisation and well before the period during which the axis becomes fixed (3). Currently, these models have not been experimentally validated, and the detailed mechanisms by which unilateral light is translated into cellular asymmetries remain elusive.

\section{Using Fucoid Zygotes to Study Intracellular $\mathrm{Ca}^{2+}$ Gradients}

The large size of the Fucus zygote (about $100 \mathrm{~m}$ ) makes it an excellent model for the microscopic visualisation of cellular processes using fluorescent markers. Fluorescent $\mathrm{Ca}^{2+}$ dyes have been used to follow intracellular $\mathrm{Ca}^{2+}$ levels in vivo in the Fucus rhizoid (e.g., $\underline{55}$ ). Growing rhizoid 
cells of Fucus exhibit a longitudinal gradient of cytoplasmic free $\mathrm{Ca}^{2+}(\underline{28})$, which is maintained by preferential $\mathrm{Ca}^{2+}$ influx in the region of the growing tip. During germination, the $\mathrm{Ca}^{2+}$ gradient at the rhizoid pole becomes more pronounced (12), and reactive oxygen species (ROS) appear to play a role in maintaining the $\mathrm{Ca}^{2+}$ gradient. In germinated Fucus serratus zygotes, ROS production correlates spatially with the $\mathrm{Ca}^{2+}$ gradient, and treatment with either ROS scavengers or NADPH oxidase inhibitors dissipates the $\mathrm{Ca}^{2+}$ gradient and reduces rhizoid growth (1ㅡ). ROS and $\mathrm{Ca}^{2+}$ also appear to function in a positive feedback loop, as the modulation of $\mathrm{Ca}^{2+}$, by either addition of a bis(2-aminophenoxy)ethane tetraacetic acid (BAPTA) buffer (which dissipates the gradient) or by increasing $\mathrm{Ca}^{2+}$ levels, results in modulation of ROS levels $(\underline{28}, \underline{41})$. Fucoid zygotes were one of the first eukaryotic model systems where tight coordination between the spatial and temporal dynamics of ROS and cellular $\mathrm{Ca}^{2+}$ gradients was observed in vivo $(\underline{33}, \underline{40})$. The Fucus zygote was also the first non-animal system in which $\mathrm{Ca}^{2+}$ release from single channels or groups of channels in the endoplasmic reticulum was described (ㄷ5).

Intracellular $\mathrm{Ca}^{2+}$ levels within the zygote are remarkably dynamic, quickly responding to external stimuli such as osmotic fluctuations. The $\mathrm{Ca}^{2+}$ gradients formed within the cell have been shown to involve both $\mathrm{Ca}^{2+}$ influx and release of $\mathrm{Ca}^{2+}$ from intracellular stores (mitochondria and endoplasmic reticulum) in apical and subapical regions of the rhizoid $(\underline{40}, \underline{55})$.

\section{$\mathrm{Ca}^{2+}$ Signalling and the Cell Cycle}

Synchronisation between cell polarisation and cell cycle progression is critical for zygote development in eukaryotes, and both processes rely on evolutionarily conserved mechanisms: the cytoskeletal actin nucleation machinery and cyclin/cyclin-dependent kinase (CDK) activity, respectively (105). These conserved mechanisms are, in turn, coordinated by cell cycle checkpoints which ensure that asymmetric cell division events occur in the correct order ( $\underline{62})$, with important impacts on multicellular patterning in the adult organism ( $\underline{69})$. The possibility of obtaining large populations of synchronously released gametes and the length of the first cell cycle (24 h), which allows clear temporal separation between cell cycle phases, have made fucoid algae powerful experimental systems for cell cycle studies. For example, the Fucus zygote has provided evidence for a link between intracellular $\mathrm{Ca}^{2+}$ signals and the interdependence of polarization and cell cycle progression during embryogenesis (27). The acquisition of polarity in fucoid zygotes is tightly coordinated with the timing and orientation of the first asymmetric division, with zygotes having to pass through a G1/S-phase checkpoint before the polarization axis can be fixed (녀). 
Inhibition of CDK proteins by tyrosine phosphorylation at the S/M DNA replication checkpoint was first demonstrated in fucoid zygotes (느), and this process was later shown to be conserved in Arabidopsis thaliana (45).

The Fucus zygote lacks the canonical fast $\mathrm{Ca}^{2+}$ waves that are required to reactivate the cell cycle following fertilisation in animals (118). Instead, distinct, slow, localized $\mathrm{Ca}^{2+}$ elevations are associated with fertilization and S-phase progression, and both S phase and zygotic polarisation are dependent on pre-S-phase $\mathrm{Ca}^{2+}$ increases $(\underline{20}, \underline{112}, \underline{120})$. Subsequent cell cycle progression through $\mathrm{M}$ phase is independent of localized actin polymerization and zygotic polarization. The absence of such morphogenesis checkpoints, together with the $\mathrm{Ca}^{2+}$ dependencies of both $\mathrm{S}$ phase and polarisation, demonstrates that regulation of zygotic division in the brown algae differs markedly from that in other model systems, such as yeast and Drosophila $(\underline{20}, \underline{29}, \underline{117})$.

\section{The Role of the Cell Wall in Polarisation and Germination}

Investigations using the Fucus zygote as a model have provided insights into the role of cell walls in the mechanisms underpinning polarisation and germination (e.g., 130). Brown algal cell walls are composed predominantly of polysaccharides, together with smaller amounts of phenols, proteins, and halide compounds. Sulphated fucans and alginates are the major cell wall matrix polysaccharides $(\underline{47}, \underline{130})$, and, in contrast to plant cells, beta-glucans (i.e. cellulose, mixed linkage glucan) are minor cell wall components. Chimeric arabinogalactan proteins (AGPs), a complex family of proteoglycans found in land plant cell walls, are also cell surface constituents in brown algae (드). Studies conducted to locate the main classes of polymers at the cell surface of developing Fucus zygotes have suggested that cellulose and alginates are the first polysaccharides to be deposited into the wall after fertilization and they are deposited uniformly over the cell surface $(\underline{115})$. Cell wall deposition is required for polar axis fixation ( $\underline{76})$. In particular, polar axis establishment is associated with targeted deposition of sulphated fucans at the rhizoid pole ( $\underline{15}$, 115). The requirement for localised secretion of cell wall components during zygote polarisation has led to models for polar axis determination based on the formation of axis-stabilising complexes comprising trans-plasma membrane links between sulphated polysaccharides in the cell wall and the cytoskeleton $(25,114)$. The unequivocal identification of the components of the axisstabilising complexes remains a challenge for future studies.

The low abundance of cellulose in the bulging wall during germination of the zygote is consistent with local cell wall loosening $(\underline{15}, \underline{106})$. Analysis of the genome of Ectocarpus sp. did 
not identify any genes encoding known deconstructing enzymes (e.g. cellulase, expansin) suggesting specific mechanisms for cell wall relaxation in brown algae $(32,97,140)$. However, an alginate lyase was recently characterised biochemically from the kelp Saccharina japonica, and genes encoding homologous enzymes are likely to be found in other brown algae such as the Fucales, once their genomes become available. The apparent absence of cellulases and expansins and the presence of alginate lyase activity suggests that alginates may be the key polymer sustaining cell wall expansion in the brown algae. During elongation, sulphated components, such as fucans and/or polyphenols, are thought to strengthen the apical cell wall $(\underline{15}, \underline{48}, \underline{130})$.

Fucoid cell walls have been shown to be a source of the position-dependent information that is required for polarisation and fate determination at both the zygote and the two-celled embryo stages $(\underline{13})$. Positional information in the cell wall appears to be required to fix the axis of polarity and to direct the future development of the embryo (14). After the two-cell stage, the cell wall plays a role in maintaining apical-basal polarity in intact cells. Intercellular communication via diffusible, apoplastic factors has been suggested to be crucial for cell fate regulation (21), but the nature of these factor(s) remains to be discovered.

In conclusion, studies using fucoid zygotes have shed light on the cellular mechanisms underlying de novo acquisition of polarity. This initial polarity establishes the apical-basal polarity of the multicellular embryo and the multicellular pattern of the adult organism. Acquisition of polarity involves the translation of external signals into spatial information within the cell via photoreceptor activation at the plasma membrane. Fixation of the polar axis involves interactions between the cytoskeleton, the plasma membrane, and the cell wall (27). Fucoid model systems have increased our understanding of the roles of both the cell wall and of intercellular communication via diffusible signals in body pattern formation and control of cell fate in the multicellular embryo (르).

While fucoids are unquestionably excellent models for cell biology and biochemistry, their long life cycles and their relatively large body size preclude genetic methodologies. Moreover, no stable reverse genetic approaches have been described for fucoids, although Fucus serratus embryos have been shown to possess a functional RNA interference (RNAi) system ( $\underline{53}$ ). RNAi can therefore be exploited to investigate gene function during embryogenesis. Note that an increasing number of resources are becoming available for the Fucales, including transcriptomes (e.g., 95, 123) and genomes (G. Hoarau, personal communication) (Table 1). 
Table 1 Brown algal model species

\begin{tabular}{|c|c|c|c|c|c|}
\hline Order & Species & $\begin{array}{l}\text { Genome } \\
\text { size } \\
(\mathrm{Mb})\end{array}$ & $\begin{array}{l}\text { Genome } \\
\text { sequence } \\
\text { status }\end{array}$ & $\begin{array}{l}\text { Resources } \\
\text { available }\end{array}$ & $\begin{array}{l}\text { Major biological questions } \\
\text { studied }\end{array}$ \\
\hline Ectocarpales & Ectocarpus sp. & 214 & $\begin{array}{l}\text { Published, } \\
\text { v2 version }\end{array}$ & $\begin{array}{l}\text { Genome } \\
\text { sequence, RNA- } \\
\text { seq, genetic } \\
\text { maps, QTLs, } \\
\text { segregating } \\
\text { families, genetic } \\
\text { mutants, RNA } \\
\text { interference, } \\
\text { large strain } \\
\text { collection }\end{array}$ & $\begin{array}{l}\text { Life cycle, sex determination, } \\
\text { development, general } \\
\text { metabolism, cell wall } \\
\text { metabolism, alga-microbe } \\
\text { symbioses }\end{array}$ \\
\hline Fucales & $\begin{array}{l}\text { Fucus } \\
\text { vesiculosus }\end{array}$ & 1,140 & In progress & $\begin{array}{l}\text { Male and female } \\
\text { RNA-seq, RNA } \\
\text { interference }\end{array}$ & $\begin{array}{l}\text { Early embryo development, cell } \\
\text { cycle, polarisation, sex-biased } \\
\text { gene expression, polyploidy }\end{array}$ \\
\hline Laminariales & $\begin{array}{l}\text { Saccharina } \\
\text { japonica }\end{array}$ & 537 & Published & $\begin{array}{l}\text { Genome } \\
\text { sequence, genetic } \\
\text { maps, QTLs, } \\
\text { strain and } \\
\text { cultivar } \\
\text { collections }\end{array}$ & Metabolism, domestication \\
\hline Dictyotales & $\begin{array}{l}\text { Dictyota } \\
\text { dichotoma }\end{array}$ & 312 & In progress & $\begin{array}{l}\text { Transcriptome, } \\
\text { RNA-seq, strain } \\
\text { collections }\end{array}$ & $\begin{array}{l}\text { Polarisation, zygote } \\
\text { development, auxin responses }\end{array}$ \\
\hline
\end{tabular}

Abbreviation: QTL, quantitative trait locus.

\section{Dictyota dichotoma, an Emerging Model}

Dictyota dichotoma has recently emerged as a new experimental model to study early embryogenesis, representing an alternative to Fucus zygotes. The life cycle of D. dichotoma can be completed under laboratory conditions in two months, and sporogenesis (i.e., spore production through meiosis) can be triggered by nutrient depletion and red light conditions. This is a significant advantage compared with fucoid algae (see above), where it may take several years to 
complete their life cycle under laboratory conditions. These practical advantages open the possibility of applying classical genetic approaches to $D$. dichotoma.

Recently, D. dichotoma zygotes have provided evidence that cell polarisation is established in two steps that are under the control of two life cycle stages: First, the zygote elongates rapidly after egg activation according to a maternally (gametophytic) predetermined axis. Second, the direction of polarisation is determined by the direction of the light in a second step that is under zygotic (sporophytic) control. This two-step process contrasts with the canonical process of cell polarisation described in other eukaryotes, where the axis and direction of polarisation are determined simultaneously when polar localisation of intrinsic factors is established $(\underline{1}, \underline{18})$.

D. dichotoma is also being used to investigate a long-standing question about the putative roles of auxins in brown algae. While auxin has a well-established and crucial role in a range of developmental processes in the green lineage ( $\underline{79})$, the question of whether plant hormones, such as auxin, are involved in the growth and development of brown algae has been and remains a matter of debate. Treatment with the auxin transport inhibitor N-1-naphthylphthalamic acid (NPA) and exogenous addition of an auxin, indole-3-acetic acid (IAA), have been reported to have an effect on polarisation, axis formation, and apical-basal pattern formation and these treatments also induced the production of multiple rhizoids or branched rhizoids in embryos of Fucus distichus (11). These experiments could not be replicated (22) but IAA has recently been detected in $D$. dichotoma germlings and mature tissue (19). D. dichotoma embryos normally produce a rhizoid from one pole and a thallus meristem from the other, but addition of exogenous auxins to zygotes affected polarisation, and both poles of the spheroidal embryo developed into rhizoids instead (19). These results argue for a role for auxin or auxin analogues during the apical-basal patterning of these embryos. Note that few homologs of auxin transport and signalling genes have been identified in the genome of Ectocarpus (모). As Ectocarpus is characterized by a relatively simple, filamentous morphology and a relatively small genome, it has been argued that genome reduction and developmental simplification could have erased traces of auxin signalling $(\underline{16}, \underline{19})$. Genome sequence information for additional brown algal species will help to solve this controversy in the future. Currently there are no genome sequences available for Fucus species or D. dichotoma, although a considerable amount of transcriptomic data exists $(\underline{18}, \underline{95})$ (Table 1$)$.

\section{ECTOCARPUS}




\section{Ectocarpus, a Model Organism for the Brown Algae}

During the last decade, the brown alga Ectocarpus has emerged as a general model system for genetic and genomic analyses of brown algal biological processes $(\underline{24}, \underline{30}, \underline{38}, \underline{109})$. Ectocarpus is a small filamentous brown alga that is found in temperate coastal regions worldwide. Ectocarpus was originally developed as a model system by Dieter Müller and colleagues at the University of Konstanz (100-102). The entire life history of Ectocarpus siliculosus from Naples was described by Müller (9) , using clonal cultures and chromosome counts. This life history involves an alternation between a sporophyte generation and a dioicous gametophyte generation, and sex is determined after meiosis, depending on whether the daughter cells inherit a $\mathrm{V}$ (male) or a $\mathrm{U}$ (female) sex chromosome (2, $\underline{99}$ ) (Figure 2).

Research on Ectocarpus has a long history ( $\underline{30})$ and this was one of the reasons underlying the choice of this species as a genetic and genomic model organism for the brown algae ( $\underline{109})$. Other important arguments for selecting Ectocarpus included its small size, the fact that its entire life cycle can be completed relatively rapidly ( 3 months) in the laboratory, its high fertility, and the ease with which genetic crosses and mutant screens can be performed $(\underline{109}, \underline{110})$. Finally, many ecotypes are available from across the world, and strains can be easily maintained as stock cultures under low light and low temperature conditions (ㅁ9).

Following the selection of Ectocarpus sp. as a model for the brown algae, a considerable effort was invested in the development of genomic and genetic tools for this organism. The most noteworthy of these was the assembly and analysis of the complete $214 \mathrm{Mbp}$ genome sequence $(\underline{32}, \underline{44})$, together with the development of a range of molecular tools, including RNAi

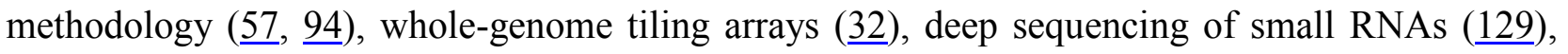
forward genetic mutant screens $(\underline{5}, \underline{56}, \underline{57}, \underline{110})$, sequence-tagged genetic maps $(\underline{7}, \underline{44}, \underline{64})$,

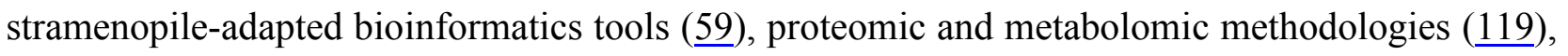
and approaches to study epigenetic processes such as post translational modifications of histones (23) (Table 1). This array of tools and resources now makes it possible to use Ectocarpus as a model to investigate the molecular mechanisms underlying diverse aspects of brown algal biology. The following sections describe advances that have been made in several different areas using Ectocarpus as a model system.

\section{Life Cycle Regulation}


Multicellular organisms from diverse groups across the eukaryotic tree exhibit a variety of life cycles, differing in the relative importance of the diploid and haploid phases. For most animal species, the diploid phase of the life cycle is the only multicellular stage, whereas organisms such as plants, and red and brown algae exhibit an alternation between two multicellular generations: a diploid sporophyte and a haploid gametophyte. The gametophyte produces the gametes, which, when they fuse, produce a sporophyte. In turn, spores produced by meiosis in the sporophyte give rise to the gametophyte ( $\underline{37})$. The brown algae are a particularly interesting group for the study of life cycle regulation and evolution because they exhibit a broad range of different cycles, ranging from isomorphic or heteromorphic haploid-diploid (with two morphologically identical or very dissimilar generations) to diploid (with only one multicellular generation) (Figure 2).

In organisms that alternate between gametophyte and sporophyte generations, the developmental program for each generation must be deployed at a precise point in the life cycle (37). In recent years, Ectocarpus sp. has emerged as a powerful model to study life cycle regulation, specifically the molecular mechanisms underlying the alternation between the gametophyte and sporophyte generations $(\underline{5}, \underline{34}, \underline{35})$. Work using Ectocarpus as a model provided evidence that the alternation between gametophyte and sporophyte programs of development is under genetic control (99). Mutant screens and gene cloning identified two genetic loci (OUROBOROS and SAMSARA) that, when mutated, cause complete conversion of a sporophyte into a gametophyte $(\underline{5}, \underline{35})$. These two genes encode TALE (three amino acid loop extension (TALE) homeodomain (HD) transcription factors (TFs). In the unicellular alga Chlamydomonas, gamete fusion is followed by the heterodimerisation of two mating type-specific TALE HD TFs, GSM1 and GSP1, and this heterodimer regulates zygote-specific gene expression (77). In mosses, KNOX and BEL class TALE HD TFs are master regulators of the sporophyte developmental program $(\underline{66}, \underline{124})$. Distantly -related homeodomain or homeodomain-like proteins act as mating type factors in both fungi and social amoebae ( $\underline{63}, \underline{67}, \underline{103}, \underline{134})$. In some fungi (Basidiomycetes), these proteins regulate several processes during sexual developmental, such as the formation of filaments, basidia, and spores $(\underline{10}, \underline{67}, \underline{73})$. TALE-HD-TF-based life cycle regulation systems therefore appear to have an extremely ancient origin. It now remains to be explored whether such proteins control life cycles and developmental programs in other multicellular organisms, such as animals. 
Non-cell autonomous factors can also influence the whether Ectocarpus sp. cells develop as a sporophyte or a gametophyte ( $(6)$. The initial cells of the gametophyte generation (meio-spores) switch their developmental fate in the presence of sporophyte tissue or cell-free, sporophyteconditioned medium and become fully functional sporophytes. A functional ORO gene is necessary for the reprogramming factor to induce a developmental switch (므). ORO may therefore be part of the regulatory network targeted by the factor. Recent investigations aimed at obtaining information about the biochemical character of the diffusible factor have provided that the factor may correspond to an arabinogalactan protein (AGP). Mass spectrometry analysis of sporophyteconditioned medium (SCM) identified several proteins, one of which is predicted to contain an AGP core protein domain, and AGP glycan epitopes were detected in a concentrated SCM preparation using immunoblotting. Moreover, SCM activity was reduced following incubation with an AGP-reactive Yariv reagent, and the biological activity of the sporophyte-inducing factor could be mimicked by the addition of either a preparation of land plant AGPs (gum arabic) or arabinogalactans (Larcoll) (138).

In conclusion, studies using Ectocarpus have made important advances in our understanding of life cycle regulation in the brown algae but also point the way to identifying new biological functions for the recently discovered AGPs in this lineage ( $\underline{65})$. Moreover, the observation that treatment with gum arabic or Larcoll induces switching to the sporophyte program provides highly useful tools to manipulate brown algal life cycles. These tools will be useful for future studies aimed at manipulating and characterising the genetic pathway implemented by the ORO and SAM proteins.

\section{Characterisation of Haploid Sexual Systems}

Experiments with Ectocarpus have been crucial to elucidate the molecular basis of sex determination and differentiation in haploid sexual systems. Traditionally, studies on sex determination and sex chromosomes have employed a few well-studied animal and plant systems, notably mammals, birds, Drosophila, and the plant Silene latifolia, all representing diploid sex determination (i.e., XY or ZW) systems. Haploid phase sex-determination systems (UV systems) (Figure 2), such as those of mosses and algae (ㅁ), had been considerably less studied until the recent advent of genomic and genetic information for the volvocine algae and Ectocarpus (ㅎ6, $132,133,133 \mathrm{a})$. In UV systems, sex is determined during the haploid phase of the life cycle by the

presence of either a $\mathrm{U}$ chromosome (in females) or a $\mathrm{V}$ chromosome (in males) (Figure 2). After 
meiosis in the sporophyte, the daughter cells (called meio-spores in brown algae) that inherit a $U$ chromosome will develop as (haploid) female gametophytes which at maturity will produce female gametes. If the meio-spore inherits a $\mathrm{V}$ chromosome, then it will develop into a (haploid) male gametophyte, which will produce male gametes. Gametes are produced by mitosis in the haploid male or female gametophytes in specific structures called plurilocular gametangia (Figure 2) (36).

Comparing the properties of animal and plant XY/ZW chromosomes with those of the UV chromosomes of Ectocarpus sp. has considerably improved our understanding of sex determination and differentiation. In Ectocarpus sp., suppression of recombination between the Uand V-specific regions occurred $>100$ Mya, and the non-recombining, sex-determining region (SDR) is relatively small, occupying about a one-tenth of the sex chromosome $(2,84)$. The Ectocarpus sp. UV chromosomes display some striking similarities with XY and ZW systems, such as low gene density and accumulation of repeated DNA in the SDR, underscoring the universality of processes that shape sex chromosome evolution in distant lineages. A possible explanation for the small size of the SDR was suggested by the low number of sex-biased genes, identified by a comparative transcriptomic approach, implying that sexual conflict in Ectocarpus may be insufficient to drive extensive SDR expansion $(2,93)$.

In addition to its function in sex determination, the SDR of Ectocarpus sp. has also been also shown to play a role in the regulation of gamete parthenogenesis, together with two autosomal loci (모).

The recombining regions of sex chromosomes, the 'pseudoautosomal regions' (PARs), are predicted to behave like autosomes because they recombine during meiosis (108). Theoretical considerations predicted that the PARs of UV systems should share some features with those of $\mathrm{XY}$ and ZW systems but should differ in other important aspects because of the different mechanism of inheritance of UV sex chromosomes (무). Recent work using the well-assembled Ectocarpus PARs showed that, although they recombine at a rate that is not different from that of any other region of the genome, these regions exhibit a number of structural and evolutionary features that are typically associated with regions of suppressed recombination $(\underline{8}, \underline{93})$. For instance, compared to the rest of the Ectocarpus sp. genome, the PARs have significantly accumulated genes that are up-regulated during the sporophyte generation of the life cycle, and these generation-specific genes exhibit signs of accelerated evolution. Information from 
additional, well-assembled sex chromosomes will be needed to assess whether these features are shared in PARs from other brown algal UV sex chromosomes. Current projects, such as the Sexsea project (http:/www.sb-roscoff.fr/en/team-algal-genetics/thematics/evolution-sexes-brownalgae), that is generating information for sex chromosomes for a dozen species across the brown algal phylogeny, are expected to address this and other features of sex chromosome evolution.

\section{Molecular Basis of Development in the Brown Algae}

As mentioned above, brown algae evolved complex multicellularity independently of animals and land plants. Comparative analyses of these three lineages could therefore potentially provide important general insights into the evolutionary processes that lead to the emergence of the developmental programs that underlie complex multicellularity. However, the scope for such a comparative analysis has been limited hitherto by a lack of information about brown algal developmental biology. This situation is changing as tools become available to characterize developmental processes in the brown algae at the molecular level. An important milestone was the identification of the first brown algal developmental gene (IMMEDIATE UPRIGHT), described below, by a forward genetic approach in 2017 (Figure 3) (4). Since that time, several additional developmental genes have been characterised, including the $O R O$ and $S A M$ genes (discussed in the section entitled Life Cycle Regulation above) which link life cycle progression with the implementation of the sporophyte developmental program. The following section describes how genetic approaches are being applied to Ectocarpus mutants to investigate brown algal developmental genetics. 


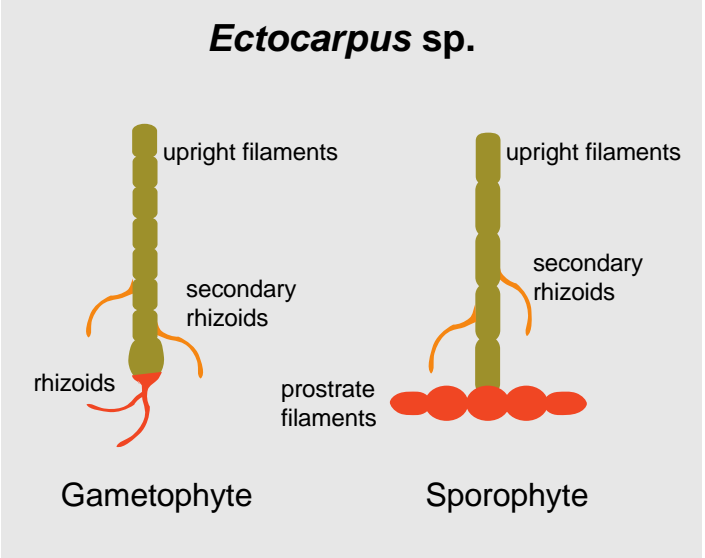

\section{Arabidopsis}

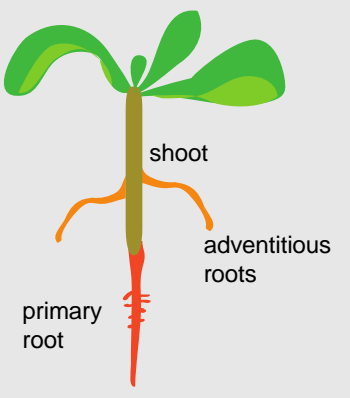

Sporophyte 
Figure 4 Basal and apical systems in Ectocarpus sp. and angiosperms (Arabidopsis). Note that these structures are analogous (not homologous) between brown algae and land plants. The cartoons are not drawn to scale.

During development, wild type Ectocarpus sp. sporophytes deploy an extensive system of basal filaments that attach the thallus to the substratum $(\underline{110})$. It is only once this basal system is deployed that the sporophyte produces the upright (apical) filaments, which grow up into the medium and produce the organism's sexual structures (plurilocular and unilocular sporangia). The gametophyte generation, in contrast, lacks an extensive basal system and is only weakly anchored to solid substrata by a small (basal) rhizoid (110) (Figure 4). In the sporophyte generation of the immediate upright (imm) mutant, the extensive basal system is replaced by a rhizoid-like structure similar to that of the gametophyte $(\underline{110})$. Based on the phenotype of this mutant, it has been suggested that the extensive basal system is a developmental innovation specific to the sporophyte generation, leading to the intriguing possibility that loss of this structure in the imm mutant reveals a default developmental program resembling that of an ancestral gametophyte form, before the acquisition of the extensive basal structure (4ㅗ). Identification of the mutated locus in the imm mutant showed that it encodes a protein of unknown function with a repeated, cysteine-rich motif (referred to as the EsV-1-7 domain). There has been a marked expansion of the EsV-1-7 domain gene family in brown algae (from zero or one gene in other stramenopiles to 91 genes in Ectocarpus sp.), suggesting a possible link between these genes and the emergence of complex multicellularity (쏘).

Mutations in another Ectocarpus sp. gene, DISTAG (DIS), cause disruption of the subcellular architecture of germinating initial cells (7) . These cellular abnormalities are associated with complete loss of all basal structures during both the sporophyte and gametophyte generations. Hence both the imm and the dis mutants indicate a certain degree of developmental equivalence between the basal systems of the two life cycle generations (both systems require DIS to develop and imm mutants cause the extensive basal system of the sporophyte to be converted into a structure similar to the gametophyte rhizoid), despite their being composed of different cell types and being markedly different in size and complexity. Genetic analysis of the DIS gene showed that it encodes a Tubulin Binding Cofactor C (TBCC) domain protein of the TBCCd1 class (57). TBCCd1 has been linked with various aspects of subcellular architecture (e.g. cell morphology, 
motility, mitosis, flagella number and functioning) in diverse organisms, including animals, Chlamydomonas, and trypanosomes $(\underline{4}, \underline{54}, \underline{58})$.

These analyses illustrate the advances that are being made in our understanding of developmental processes in brown algae using Ectocarpus as a model organism. A considerable amount of further work will be required before comprehensive comparisons can be made between developmental processes in brown algae and those of other eukaryotic lineages. However, it is already interesting that these analyses have identified both highly conserved processes, such as the involvement of TALE HD TFs in life cycle regulation and sporophyte development, and brownalgal-specific processes, such as the involvement of the $I M M$ gene, which has no homologues in either animals or land plants, in the deployment of the sporophyte basal system.

\section{Other Aspects of Brown Algal Biology}

Ectocarpus is also currently being used as a laboratory model to study several other aspects of brown algal biology, including the implementation of systems biology approaches to understand brown algal metabolism (111), biophysical approaches to study brown algal growth and morphology $(\underline{116})$, and investigations aimed at understanding interactions between brown algae and other organisms, such as symbiotic bacteria $(\underline{75})$ or pathogens $(\underline{128})$.

\section{SACCHARINA JAPONICA}

In China, where there is an extensive macroalgal aquaculture industry, efforts have been aimed directly at developing tools and resources for cultivated crop species, particularly Saccharina japonica, rather than using Ectocarpus as a model system. This approach is analogous to the use of maize or rice as model terrestrial crop species rather than the non-crop species Arabidopsis.

S. japonica has been cultivated in China since the 1930s (131). Rapid expansion of the sector in the 1950s led to the first attempts to implement selective breeding to produce new, high-yield varieties $(\underline{52})$. Since that time, many new varieties have been produced $(\underline{80}-\underline{82}, \underline{89}, \underline{131}, \underline{142}, \underline{145})$ and $S$. japonica production has increased rapidly, with Chinese production reaching ten million tonnes in 2017 (www.fao.org/3/CA1121EN/ca1121en.pdf). Most of the production is for human consumption or is fed to marine animals, but the biomass is also used to extract products such as

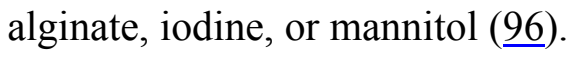


Development of $S$. japonica as a model has focused on the implementation of classical breeding approaches for crop improvement and the establishment of genomic resources to support this activity. Breeding of improved varieties has used a number of different approaches, including intra- and interspecific hybridization to increase genetic diversity and create heterosis, and the use of gametophyte cloning approaches to produce defined genetic material $(\underline{80}, \underline{81}, \underline{131}, \underline{142}, \underline{145})$. Tools for marker-based selection, such as genetic maps and quantitative trait locus (QTL) analyses, have been produced. The first genetic map was reported in 2007 and the first QTL analysis in $2010(\underline{83}, \underline{88})$. Subsequent studies have reported a series of progressively higher density genetic maps and more extensive QTL identification (무, 136, 137, 141). Sex-linked genetic markers have also been developed for S. japonica and other species of kelp $(\underline{85}, \underline{92})$.

A major landmark in $S$. japonica research was the analysis of the complete genome sequence of this species in 2015 (140). The genome has provided access to genes associated with key metabolic processes, such as cell wall (polysaccharide) and halide metabolism. In addition to protein-coding genes, various analyses have also identified different classes of noncoding genes, such as long noncoding RNAs and potential microRNAs $(\underline{31}, \underline{44}, \underline{91})$. A recent report that the $S$. japonica genome contains a low level of methylated cytosine bases ( $\underline{51})$ represents a first step towards the development of epigenetic methodologies for this species, with potential future exploitation of epigenetic information for strain improvement.

In addition, genetic and genomic tools have been used to retrace the domestication of $S$. japonica and to evaluate the genetic composition of present-day cultivated varieties. S. japonica originates from cold-temperature coastal regions of northern Japan, northwest Korea and eastern Russia. The species was first introduced into northern China, and then cultivation spread southwards along the Chinese eastern coast, with a concomitant loss of genetic diversity (140, $143, \underline{144})$. An understanding of genetic events during this process will be useful for the design of future marker-based strategies for strain improvement.

The methodologies developed for S. japonica are currently being extended to other kelp species of economic interest, including Undaria pinnatifida, for example, for which a genetic map (126) and a complete genome assembly (H. S. Yoon, personal communication) have been generated. Resources are also being established for the giant kelp Macrocystis pyrifera (135).

\section{CROSS-SPECIES COMPARISONS AND EVOLUTION WITHIN THE BROWN ALGAE}


Studies using the model species described above have provided important insights into diverse aspects of brown algal biology but it has often been unclear to what extent features of individual model species can be generalised to the entire brown algal lineage. One of the factors that has limited our ability to obtain a broader view of brown algal biology is has been a lack of genome data for most of the species within this group. To date, only a limited number of brown algal genome sequences are available $(\underline{44}, \underline{50}, 104,140)$, together with transcriptomic data for some additional species (8), but a number of genome projects have been initiated to address this problem, including the Phaeoexplorer project, which is generating genome sequences for 47 brown algae and four sister species (https://www.france-genomique.org/projet/phaeoexplorer/). As they become available, these new resources will not only allow us to test the generality of observations made using specific model species but may also allow the evolutionary history of brown algal traits to be traced through the entire lineage. Two recent studies have attempted to take this approach using the limited genomic resources that are currently available, building on work initially carried out using Ectocarpus. These studies included an analysis of sex chromosome evolution, which revealed significant movement of genes onto and off of the sex chromosomes (7) and a comparison of generation-biased gene expression, which found evidence for rapid turnover of this class of gene during evolution $(\underline{86})$. Both studies limited their analyses to the orders Ectocarpales and Laminariales, but this nonetheless represents about 100 million years of evolution, and the studies provide a convincing illustration of the potential of this type of comparative genomic approach.

\section{CONCLUSIONS AND FUTURE DIRECTIONS}

With the emergence of the well-resourced model organisms described above, it is now possible to efficiently address diverse questions related to brown algal biology in the laboratory. There are a number of reasons why it has been important to develop our capacity to study brown algae. First, because of their phylogenetic position, a better understanding of the brown algae will tend to provide us with a broader understanding of evolutionary processes across the eukaryotic tree, particularly key evolutionary events such as the emergence of complex multicellularity (139).

Second, compared to classical model organisms, the brown algae exhibit a number of unusual characteristics, such as diverse types of life cycle, UV sexual systems, external fertilisation, and 
novel cell wall structure. These characteristics often make brown algae particularly interesting models to address questions related to these features.

Finally, as a result of the spectacular growth of the seaweed aquaculture industry, particularly in Asia, an urgent need has emerged both for both a better understanding of several aspects of brown algal biology (e.g., reproduction, development and interactions with symbionts) and the means to efficiently improve cultivated brown algal strains.

The extensive genome resources and genetic tools developed for Ectocarpus make it the model of choice to address a broad range of fundamental research questions and to generally improve our knowledge of how brown algae function. A great deal of progress has been made in recent years in domains as diverse as early development, sex determination, metabolism, and epigenetics, but brown algae remain much less well-characterised than groups with long-standing model systems such as land plants, animals or fungi, and a significant effort will be required to address the imbalance. Ectocarpus is likely to play an important role in this process, but other brown algal models will be of interest to address specific questions. For example, for cell biology approaches, the large size of Fucus and D. dichotoma cells represents a significant advantage, and these models will continue to be of interest to explore cell biology events, particularly during early embryogenesis. It will also be of interest to transfer tools and resources from Ectocarpus sp. to new model species, particularly when these species are quite closely related to Ectocarpus but exhibit novel characteristics. One Ectocarpus species, Ectocarpus subulatus, which is able to grow in fresh water and is highly stress-resistant, represents a nice example of this type of approach $(\underline{50})$.

The emergence of model cultivated species such as $S$. japonica represents an important advance for the development of applied research strategies that take advantage of advances in fundamental research. Future research in this area is likely to see combined use of Ectocarpus as a laboratory model, together with target cultivated models such as $S$. japonica to allow both rapid generation of new knowledge and application of that knowledge.

Although recent years have seen the development of an array of genetic and genomic resources for the brown algae, there remains a pressing need for more advanced genetic tools, especially reverse genetic approaches. RNAi has been applied to study embryonic development in Fucus $(\underline{53})$ and to validate candidate mutations in Ectocarpus sp. $(\underline{57}, \underline{94})$, but this approach is currently limited to cases where phenotypes can be visualised during early development. CRISPR- 
Cas9-based genome modification and editing systems have now been developed for a broad range of eukaryotes, including stramenopiles $(\underline{107}, \underline{125})$, and a major objective for the near future will be to adapt this system for use in brown algae.

In addition, there are several other areas where new tools and resources would reinforce the utility of brown algal models. Two particularly interesting areas are transcriptomics and the exploitation of natural genetic variation. For the former, whole-organism transcriptomic data are available for several developmental and life cycle stages, but more detailed, cell-type-specific transcriptomic information would provide important information about the potential functions of expressed genes. Indirect information about gene function, such as transcriptomic data, is particularly important for unusual phylogenetic groups such as the brown algae, where a large proportion of the genes in the genome do not have any associated functional information [39\% of genes in the case of Ectocarpus (44)].

When combined with phenotypic information, natural genetic variation can also potentially provide information about gene function but this approach has not yet been used for brown algal models. Large collections of strains exist for some models, such as Ectocarpus and Saccharina, but high-throughput genotyping and phenotyping approaches need to be developed to exploit these genetic resources. Note that, depending on the model species, this approach can be used to address both fundamental and applied questions.

As the collections of tools and resources available for these models are expected to be gradually and substantially enlarged in the coming years, it is clear that brown algae will continue to make many contributions to our understanding of biology in a broad taxonomic context.

\section{DISCLOSURE STATEMENT}

The authors are not aware of any affiliations, memberships, funding, or financial holdings that might be perceived as affecting the objectivity of this review.

\section{ACKNOWLEDGMENTS}

Work in the Algal Genetics Group is supported by the Agence Nationale de la Recherche, the CNRS, Sorbonne Université, the European Research Council (ERC) (grant number. 638240) and the Agence Nationale de la Recherche (ANR) (grant number ANR-19-CE20-0028-01). 


\section{LITERATURE CITED}

1. Abrash EB, Bergmann DC. 2009. Asymmetric cell divisions: a view from plant development. Dev. Cell 16(6):783-96

2. Ahmed S, Cock JM, Pessia E, Luthringer R, Cormier A, et al. 2014. A haploid system of sex determination in the brown alga Ectocarpus sp. Curr. Biol. 24(17):1945-57

3. Alessa L, Kropf DL. 1999. F-actin marks the rhizoid pole in living Pelvetia compressa zygotes. Development 126(1):201-9

4. André J, Harrison S, Towers K, Qi X, Vaughan S, et al. 2013. The tubulin cofactor C family member TBCCD1 orchestrates cytoskeletal filament formation. J. Cell. Sci. 126(Pt. 23):535056

5. Arun A, Coelho SM, Peters AF, Bourdareau S, Peres L, et al. 2019. Convergent recruitment of TALE homeodomain life cycle regulators to direct sporophyte development in land plants and brown algae. eLife 8:e43101

6. Arun A, Peters NT, Scornet D, Peters AF, Cock JM, Coelho SM. 2013. Non-cell autonomous regulation of life cycle transitions in the model brown alga Ectocarpus. New Phytol. 197(2):503-10

7. Avia K, Coelho SM, Montecinos GJ, Cormier A, Lerck F, et al. 2017. High-density genetic map and identification of QTLs for responses to temperature and salinity stresses in the model brown alga Ectocarpus. Sci. Rep. 7:43241

8. Avia K, Lipinska AP, Mignerot L, Montecinos AE, Jamy M, et al. 2018. Genetic diversity in the UV sex chromosomes of the brown alga Ectocarpus. Genes (Basel) 9(6):286

9. Bachtrog D, Kirkpatrick M, Mank JE, McDaniel SF, Pires JC, et al. 2011. Are all sex chromosomes created equal? Trends Genet. 27(9):350-57

10. Banham AH, Asante-Owusu RN, Gottgens B, Thompson S, Kingsnorth CS, et al. 1995. An Nterminal dimerization domain permits homeodomain proteins to choose compatible partners and initiate sexual development in the mushroom Coprinus cinereus. Plant Cell 7(6):773-83

11. Basu S, Sun H, Brian L, Quatrano RL, Muday GK. 2002. Early embryo development in Fucus distichus is auxin sensitive. Plant Physiol. 130(1):292-302 
12. Berger F, Brownlee C. 1993. Ratio confocal imaging of free cytoplasmic calcium gradients in polarising and polarised Fucus zygotes. Zygote 1(1):9-15

13. Berger F, Brownlee C. 1994. Photopolarization of the Fucus sp. zygote by blue light involves a plasma membrane redox chain. Plant Physiol. 105(2):519-27

14. Berger F, Taylor A, Brownlee C. 1994. Cell fate determination by the cell wall in early Ffucus development. Science 263(5152):1421-23

15. Bisgrove SR, Kropf DL. 2001. Cell wall deposition during morphogenesis in fucoid algae. Planta 212(5-6):648-58

16. Bogaert KA, Arun A, Coelho SM, De Clerck O. 2013. Brown algae as a model for plant organogenesis. Methods Mol. Biol. 959:97-125

17. Bogaert KA, Beeckman T, De Clerck O. 2015. Photopolarization of Fucus zygotes is determined by time sensitive vectorial addition of environmental cues during axis amplification. Front. Plant Sci. 6:26

18. Bogaert KA, Beeckman T, De Clerck O. 2017. Two-step cell polarization in algal zygotes. Nat. Plants 3:16221

19. Bogaert KA, Blommaert L, Ljung K, Beeckman T, De Clerck O. 2019. Auxin function in the brown alga Dictyota dichotoma. Plant Physiol. 179(1):280-99

20. Bothwell JHF, Kisielewska J, Genner MJ, McAinsh MR, Brownlee C. 2008. $\mathrm{Ca}^{2+}$ signals coordinate zygotic polarization and cell cycle progression in the brown alga Fucus serratus. Development 135(12):2173-81

21. Bouget FY, Berger F, Brownlee C. 1998. Position dependent control of cell fate in the Fucus embryo: role of intercellular communication. Development 125(11):1999-2008

22. Bouget FY, Corellou F, Kropf DL. 2001. Fucoid algae as model organisms for investigating early embryogenesis. Cah. Biol. Mar. 42:101-107

23. Bourdareau, S., Tirichine, L., Lombard, B., Loew, D., Coelho, S.M. and Cock, J.M. (2020). Histone modifications during the life cycle of the brown alga Ectocarpus. Genome Biology, in press.

24. Brodie J, Chan CX, De Clerck O, Cock JM, Coelho SM, et al. 2017. The algal revolution. Trends Plant Sci. 22(8):726-38

25. Brownlee C, Berger F. 1995. Extracellular matrix and pattern in plant embryos: on the lookout for developmental information. Trends Genet. 11(9):344-48 
26. Brownlee C, Bouget FY. 1998. Polarity determination in Fucus: from zygote to multicellular embryo. Semin. Cell Dev. Biol. 9(2):179-85

27. Brownlee C, Bouget FY, Corellou F. 2001. Choosing sides: establishment of polarity in zygotes of fucoid algae. Semin. Cell Dev. Biol. 12(5):345-51

28. Brownlee C, Wood JW. 1986. A gradient of cytoplasmic free calcium a in growing rhizoid cells of Fucus serratus. Nature 320(6063):624-26

29. Callaini G, Dallai R, Riparbelli MG. 1992. Cytochalasin induces spindle fusion in the syncytial blastoderm of the early Drosophila embryo. Biol. Cell 74(3):249-54

30. Charrier B, Coelho S, Le Bail A, Tonon T, Michel G, et al. 2008. Development and physiology of the brown alga Ectocarpus siliculosus: two centuries of research. New Phytol. 177(2):319-32

31. Cock JM, Liu F, Duan D, Bourdareau S, Lipinska AP, et al. 2017. Rapid evolution of microRNA loci in the brown algae. Genome Biol. Evol. 9(3):740-49

32. Cock JM, Sterck L, Rouzé P, Scornet D, Allen AE, et al. 2010. The Ectocarpus genome and the independent evolution of multicellularity in brown algae. Nature 465(7298):617-21

33. Coelho SM, Brownlee C, Bothwell JHF. 2008. Feedback control of reactive oxygen and $\mathrm{Ca}^{2+}$ signaling during brown algal embryogenesis. Plant Signal. Behav. 3(8):570-72

34. Coelho SM, Godfroy O, Arun A, Le Corguillé G, Peters AF, Cock JM. 2011. Genetic regulation of life cycle transitions in the brown alga Ectocarpus. Plant Signal. Behav. 6(11):1858-60

35. Coelho SM, Godfroy O, Arun A, Le Corguillé G, Peters AF, Cock JM. 2011. OUROBOROS is a master regulator of the gametophyte to sporophyte life cycle transition in the brown alga Ectocarpus. PNAS 108(28):11518-23

36. Coelho SM, Gueno J, Lipinska AP, Cock JM, Umen JG. 2018. UV chromosomes and haploid sexual systems. Trends Plant Sci. 23(9):794-807

37. Coelho SM, Peters AF, Charrier B, Roze D, Destombe C, et al. 2007. Complex life cycles of multicellular eukaryotes: new approaches based on the use of model organisms. Gene 406(12): $152-70$

38. Coelho SM, Scornet D, Rousvoal S, Peters N, Dartevelle L, et al. 2012. Ectocarpus: a model organism for the brown algae. Cold Spring Harb. Protoc. 2012:193-98 
39. Coelho SM, Scornet D, Rousvoal S, Peters NT, Dartevelle L, et al. 2012. How to cultivate Ectocarpus. Cold Spring Harb. Protoc. 2012(2):258-61

40. Coelho SM, Taylor AR, Ryan KP, Sousa-Pinto I, Brown MT, Brownlee C. 2002. Spatiotemporal patterning of reactive oxygen production and $\mathrm{Ca}^{2+}$ wave propagation in Fucus rhizoid cells. Plant Cell 14(10):2369-81

41. Coelho SMB, Brownlee C, Bothwell JHF. 2008. A tip-high, $\mathrm{Ca}(2+)$-interdependent, reactive oxygen species gradient is associated with polarized growth in Fucus serratus zygotes. Planta 227(5):1037-46

42. Corellou F, Bisgrove SR, Kropf DL, Meijer L, Kloareg B, Bouget FY. 2000. A S/M DNA replication checkpoint prevents nuclear and cytoplasmic events of cell division including centrosomal axis alignment and inhibits activation of cyclin-dependent kinase-like proteins in fucoid zygotes. Development 127(8):1651-60

43. Corellou F, Brownlee C, Detivaud L, Kloareg B, Bouget FY. 2001. Cell cycle in the fucus zygote parallels a somatic cell cycle but displays a unique translational regulation of cyclindependent kinases. Plant Cell 13(3):585-98

44. Cormier A, Avia K, Sterck L, Derrien T, Wucher V, et al. 2017. Re-annotation, improved large-scale assembly and establishment of a catalogue of noncoding loci for the genome of the model brown alga Ectocarpus. New Phytol. 214:219-32

45. De Schutter K, Joubes J, Cools T, Verkest A, Corellou F, et al. 2007. Arabidopsis WEE1 kinase controls cell cycle arrest in response to activation of the DNA integrity checkpoint. Plant Cell 19(1):211-25

46. Deniaud-Bouet E, Hardouin K, Potin P, Kloareg B, Herve C. 2017. A review about brown algal cell walls and fucose-containing sulfated polysaccharides: cCell wall context, biomedical properties and key research challenges. Carbohydr. Polym. 175:395-408

47. Deniaud-Bouet E, Kervarec N, Michel G, Tonon T, Kloareg B, Herve C. 2014. Chemical and enzymatic fractionation of cell walls from Fucales: insights into the structure of the extracellular matrix of brown algae. Ann. Bot. 114(6):1203-16

48. Deleted in proof Deniaud-Bouet E, Kervarec N, Michel G, Tonon T, Kloareg B, Herve C. 2014. Chemical and enzymatic fractionation of cell walls from Fucales: insights into the structure of the extracellular matrix of brown algae. Ann. Bot. 114(6):1203-16 
49. Dittami SM, Barbeyron T, Boyen C, Cambefort J, Collet G, et al. 2014. Genome and metabolic network of "Candidatus Phaeomarinobacter ectocarpi" Ec32, a new candidate genus of Alphaproteobacteria frequently associated with brown algae. Front. Genet. 5:241

50. Dittami SM, Corre E, Brillet-Gueguen L, Lipinska AP, Pontoizeau N, et al. 2020. The genome of Ectocarpus subulatus - - a highly stress-tolerant brown alga. Mar. Genom. In press., p. 100740

51. Fan X, Han W, Teng L, Jiang P, Zhang X, et al. 2020. Single-base methylome profiling of the giant kelp Saccharina japonica reveals significant differences in DNA methylation to microalgae and plants. New Phytol. 225(1):234-49

52. Fang T, Li J. 1966. The breeding of a long-frond variety of Laminaria japonica Aresch. Oceanol. Limnol. Sin. 8:43-50

53. Farnham G, Strittmatter M, Coelho S, Cock JM, Brownlee C. 2013. Gene silencing in Fucus embryos: developmental consequences of RNAi-mediated cytoskeletal disruption. J. Phycol. 49(5):819-29

54. Feldman JL, Marshall WF. 2009. ASQ2 encodes a TBCC-like protein required for motherdaughter centriole linkage and mitotic spindle orientation. Curr. Biol. 19(14):1238-43

55. Goddard H, Manison NF, Tomos D, Brownlee C. 2000. Elemental propagation of calcium signals in response-specific patterns determined by environmental stimulus strength. PNAS 97(4):1932-37

56. Godfroy O, Peters AF, Coelho SM, Cock JM. 2015. Genome-wide comparison of ultraviolet and ethyl methanesulphonate mutagenesis methods for the brown alga Ectocarpus. Mar. Genom. 24:109-13

57. Godfroy O, Uji T, Nagasato C, Lipinska AP, Scornet D, et al. 2017. DISTAG/TBCCd1 is required for basal cell fate determination in Ectocarpus. Plant Cell 29:3102-22

58. Goncalves J, Nolasco S, Nascimento R, Lopez Fanarraga M, Zabala JC, Soares H. 2010. TBCCD1, a new centrosomal protein, is required for centrosome and Golgi apparatus positioning. EMBO Rep. 11(3):194-200

59. Gschloessl B, Guermeur Y, Cock JM. 2008. HECTAR: a method to predict subcellular targeting in heterokonts. BMC Bioinform. 9:393

60. Hable WE, Kropf DL. 1998. Roles of secretion and the cytoskeleton in cell adhesion and polarity establishment in Pelvetia compressa zygotes. Dev. Biol. 198(1):45-56 
61. Hable WE, Kropf DL. 2000. Sperm entry induces polarity in fucoid zygotes. Development 127(3):493-501

62. Hartwell LH, Weinert TA. 1989. Checkpoints: controls that ensure the order of cell cycle events. Science 246(4930):629-34

63. Hedgethorne K, Eustermann S, Yang J-C, Ogden TEH, Neuhaus D, Bloomfield G. 2017. Homeodomain-like DNA binding proteins control the haploid-to-diploid transition in Dictyostelium. Sci. Adv. 3(9):e1602937

64. Heesch S, Cho GY, Peters AF, Le Corguillé G, Falentin C, et al. 2010. A sequence-tagged genetic map for the brown alga Ectocarpus siliculosus provides large-scale assembly of the genome sequence. New Phytol. 188(1):42-51

65. Herve C, Simeon A, Jam M, Cassin A, Johnson KL, et al. 2016. Arabinogalactan proteins have deep roots in eukaryotes: identification of genes and epitopes in brown algae and their role in Fucus serratus embryo development. New Phytol. 209(4):1428-41

66. Horst NA, Katz A, Pereman I, Decker EL, Ohad N, Reski R. 2016. A single homeobox gene triggers phase transition, embryogenesis and asexual reproduction. Nat. Plants 2:15209

67. Hull CM, Boily M-J, Heitman J. 2005. Sex-specific homeodomain proteins Sxi1<alpha and Sxi2a coordinately regulate sexual development in Cryptococcus neoformans. Eukaryot. Cell 4(3):526-35

68. Hurd AM. 1920. Effect of unilateral monochromatic light and group orientation on the polarity of germinating Fucus spores. Bot.anical Gaz.ette 70(1):25-50

69. Huynh J-R, St Johnston D. 2004. The origin of asymmetry: early polarisation of the Drosophila germline cyst and oocyte. Curr. Biol. 14(11):R438-49

70. Immler S, Otto SP. 2015. The evolution of sex chromosomes in organisms with separate haploid sexes. Evolution 69(3):694-708

71. Jaffe LF. 1958. Tropistic responses of zygotes of the Fucaceae to polarized light. Exp. Cell Res. 15(2):282-99

72. Ji S-Q, Wang B, Lu M, Li F-L. 2016. Direct bioconversion of brown algae into ethanol by thermophilic bacterium Defluviitalea phaphyphila. Biotechnol. Biofuels 9(1):81

73. Kamper J, Reichmann M, Romeis T, Bolker M, Kahmann R. 1995. Multiallelic recognition: nonself-dependent dimerization of the $\mathrm{bE}$ and $\mathrm{bW}$ homeodomain proteins in Ustilago maydis. Cell 81(1):73-83 
74. Kawai H, Hanyuda T, Draisma SGA, Wilce RT, Andersen RA. 2015. Molecular phylogeny of two unusual brown algae, Phaeostrophion irregulare and Platysiphon glacialis, proposal of the Stschapoviales ord. nov. and Platysiphonaceae fam. nov., and a re-examination of divergence times for brown algal orders. J. Phycol. 51(5):918-28

75. KleinJan H, Jeanthon C, Boyen C, Dittami SM. 2017. Exploring the cultivable Ectocarpus microbiome. Front. Microbiol. 8:2456

76. Kropf DL, Kloareg B, Quatrano RS. 1988. Cell wall is required for fixation of the embryonic axis in Fucus zygotes. Science 239(4836):187-90

77. Lee J-H, Lin H, Joo S, Goodenough U. 2008. Early sexual origins of homeoprotein heterodimerization and evolution of the plant KNOX/BELL family. Cell 133(5):829-40

78. Leebens-Mack JH, Barker MS, Carpenter EJ, Deyholos MK, Gitzendanner MA, et al. 2019. One thousand plant transcriptomes and the phylogenomics of green plants. Nature 574(7780):679-85

79. Leyser O. 2018. Auxin signaling. Plant Physiol. 176(1):465-79

80. Li X, Cong Y, Yang G, Shi Y, Qu S, et al. 2007. Trait evaluation and trial cultivation of Dongfang No. 2, the hybrid of a male gametophyte clone of Laminaria longissima (Laminariales, Phaeophyta) and a female one of L. japonica. J. Appl. Phycol. 19:139-51

81. Li X, Liu J, Cong Y, Qu S, Zhang Z, et al. 2008. Breeding and trial cultivation of Dongfang No. 3, a hybrid of Laminaria gametophyte clones with a more than intraspecific but less than interspecific relationship. Aquaculture 280(1):76-80

82. Li X, Zhang Z, Qu S, Liang G, Sun J, et al. 2016. Improving seedless kelp (Saccharina japonica) during its domestication by hybridizing gametophytes and seedling-raising from sporophytes. Sci. Rep. 6:21255

83. Li Y, Yang Y, Liu J, Wang X, Gao T, Duan D. 2007. Genetic mapping of Laminaria japonica and L. longissima using amplified fragment length polymorphism markers in a "two-way pseudo-testcross" strategy. J. Integr. Plant Biol. 49(3):392-400

84. Lipinska A, Cormier A, Luthringer R, Peters AF, Corre E, et al. 2015. Sexual dimorphism and the evolution of sex-biased gene expression in the brown alga ectocarpus. Mol. Biol. Evol. 32(6):1581-97

85. Lipinska AP, Ahmed S, Peters AF, Faugeron S, Cock JM, Coelho SM. 2015. Development of PCR-based markers to determine the sex of kelps. PLOS ONE 10(10):e140535 
86. Lipinska AP, Serrano-Serrano ML, Cormier A, Peters AF, Kogame K, et al. 2019. Rapid turnover of life-cycle-related genes in the brown algae. Genome Biol. 20(1):35

87. Lipinska AP, Toda NRT, Heesch S, Peters AF, Cock JM, Coelho SM. 2017. Multiple gene movements into and out of haploid sex chromosomes. Genome Biol. 18(1):104

88. Liu F, Shao Z, Zhang H, Liu J, Wang X, Duan D. 2010. QTL mapping for frond length and width in Laminaria japonica Aresch (Laminarales, Phaeophyta) using AFLP and SSR markers. Mar. Biotechnol. (N.Y.) 12(4):386-94

89. Liu F, Sun X, Wang F, Wang W, Liang Z, et al. 2014. Breeding, economic traits evaluation, and commercial cultivation of a new Saccharina variety "Huangguan No. 1." Aquacult Int. 22(5):1665-75

90. Liu F, Wang X, Liu J, Fu W, Duan D, Yang Y. 2009. Genetic mapping of the Laminaria Japonica (Llaminarales, Phaeophyta) using amplified fragment length polymorphism markers1. J. Phycol. 45(5):1228-33

91. Liu F, Wang W, Sun X, Liang Z, Wang F. 2015. Conserved and novel heat stress-responsive microRNAs were identified by deep sequencing in Saccharina japonica (Laminariales, Phaeophyta). Plant Cell Environ. 38(7):1357-67

92. Liu Y, Bi Y, Gu J, Li L, Zhou Z. 2012. Localization of a female-specific marker on the chromosomes of the brown seaweed Saccharina japonica using fluorescence in situ hybridization. PLOS ONE 7(11):e48784

93. Luthringer R, Lipinska AP, Roze D, Cormier A, Macaisne N, et al. 2015. The pseudoautosomal regions of the U/V sex chromosomes of the brown alga Ectocarpus exhibit unusual features. Mol. Biol. Evol. 32(11):2973-85

94. Macaisne N, Liu F, Scornet D, Peters AF, Lipinska A, et al. 2017. The Ectocarpus IMMEDIATE UPRIGHT gene encodes a member of a novel family of cysteine-rich proteins that have an unusual distribution across the eukaryotes. Development 144:409-18

95. Martins MJF, Mota CF, Pearson GA. 2013. Sex-biased gene expression in the brown alga Fucus vesiculosus. BMC Genom. 14:294

96. McHugh DJ. 2003. A guide to the seaweed industry. In FAO Fisheries Tech.nical Pap.er No 441, ed. Food Agric. Organ. U. N., Rome, Italy: FAO 
97. Michel G, Tonon T, Scornet D, Cock JM, Kloareg B. 2010. Central and storage carbon metabolism of the brown alga Ectocarpus siliculosus: insights into the origin and evolution of storage carbohydrates in Eukaryotes. New Phytol. 188(1):67-81

98. Mignerot L, Avia K, Luthringer R, Lipinska AP, Peters AF, et al. 2019. A key role for sex chromosomes in the regulation of parthenogenesis in the brown alga Ectocarpus. PLOS Genet. 15(6):e1008211

99. Müller DG. 1964. Life-cycle of Ectocarpus siliculosus from Naples, Italy. Nature 203:1402

100. Müller DG. 1991. Mendelian segregation of a virus genome during host meiosis in the marine brown alga Ectocarpus siliculosus. J. Plant Physiol. 137:739-43

101. Müller DG, Jaenicke L, Donike M, Akintobi T. 1971. Sex attractant in a brown alga: chemical structure. Science 171:815-17

102. Müller DG, Kapp M, Knippers R. 1998. Viruses in marine brown algae. Adv. Virus Res. $50: 49-67$

103. Nasmyth K, Shore D. 1987. Transcriptional regulation in the yeast life cycle. Science 237(4819):1162-70

104. Nishitsuji K, Arimoto A, Iwai K, Sudo Y, Hisata K, et al. 2016. A draft genome of the brown alga, Cladosiphon okamuranus, S-strain: a platform for future studies of 'mozuku' biology. DNA Res.: Int. J. Rap. Publ. Rep. Genes Genomes 23(6):561-70

105. Noatynska A, Tavernier N, Gotta M, Pintard L. 2013. Coordinating cell polarity and cell cycle progression: What can we learn from flies and worms? Open Biol. 3(8):130083-130083

106. Novotny AM, Forman M. 1975. The composition and development of cell walls of Fucus embryos. Planta 122(1):67-78

107. Nymark M, Sharma AK, Sparstad T, Bones AM, Winge P. 2016. A CRISPR/Cas9 system adapted for gene editing in marine algae. Sci. Rep. 6:24951

108. Otto SP, Pannell JR, Peichel CL, Ashman T-L, Charlesworth D, et al. 2011. About PAR: the distinct evolutionary dynamics of the pseudoautosomal region. Trends Genet. 27(9):358-67

109. Peters AF, Marie D, Scornet D, Kloareg B, Mark Cock J. 2004. Proposal of Ectocarpus siliculosus (Ectocarpales, Phaeophyceae) as a model organism for brown algal genetics and genomics1,2. J. Phycol. 40(6):1079-88 
110. Peters AF, Scornet D, Ratin M, Charrier B, Monnier A, et al. 2008. Life-cycle-generationspecific developmental processes are modified in the immediate upright mutant of the brown alga Ectocarpus siliculosus. Development 135(8):1503-12

111. Prigent S, Collet G, Dittami SM, Delage L, Ethis de Corny F, et al. 2014. The genome-scale metabolic network of Ectocarpus siliculosus (EctoGEM): a resource to study brown algal physiology and beyond. Plant J. 80(2):367-81

112. Pu R, Robinson KR. 1998. Cytoplasmic calcium gradients and calmodulin in the early development of the fucoid alga Pelvetia compressa. J. Cell Sci. 111(Pt. 21):3197-207

113. Quatrano RS. 1997. Cortical asymmetries direct the establishment of cell polarity and the plane of cell division in the Fucus embryo. Cold Spring Harb. Symp. Quant. Biol. 62:65-70

114. Quatrano RS, Shaw SL. Role of the cell wall in the determination of cell polarity and the plane of cell division in Fucus embryos. Trends Plant Sci. 2(1):15-21

115. Quatrano RS, Stevens PT. 1976. Cell wall assembly in Fucus zygotes: I. Characterization of the polysaccharide components. Plant Physiol. 58(2):224-31

116. Rabille H, Billoud B, Tesson B, Le Panse S, Rolland E, Charrier B. 2019. The brown algal mode of tip growth: keeping stress under control. PLOS Biol. 17(1):e2005258

117. Raff JW, Glover DM. 1988. Nuclear and cytoplasmic mitotic cycles continue in Drosophila embryos in which DNA synthesis is inhibited with aphidicolin. J. Cell Biol. 107(6 Pt 1):200919

118. Rauh NR, Schmidt A, Bormann J, Nigg EA, Mayer TU. 2005. Calcium triggers exit from meiosis II by targeting the APC/C inhibitor XErp1 for degradation. Nature 437(7061):104852

119. Ritter A, Dittami SM, Goulitquer S, Correa JA, Boyen C, et al. 2014. Transcriptomic and metabolomic analysis of copper stress acclimation in Ectocarpus siliculosus highlights signaling and tolerance mechanisms in brown algae. BMC Plant Biol. 14:116

120. Roberts SK, Gillot I, Brownlee C. 1994. Cytoplasmic calcium and Fucus egg activation. Development 120(1):155-63

121. Robinson KR, Lorenzi R, Ceccarelli N, Gualtieri P. 1998. Retinal identification in Pelvetia fastigiata. Biochem. Biophys. Res. Commun. 243(3):776-78

122. Robinson KR, Miller BJ. 1997. The coupling of cyclic GMP and photopolarization of Pelvetia zygotes. Dev. Biol. 187(1):125-30 
123. Rugiu L, Panova M, Pereyra RT, Jormalainen V. 2020. Gene regulatory response to hyposalinity in the brown seaweed Fucus vesiculosus. BMC Genom. 21(1):42

124. Sakakibara K, Ando S, Yip HK, Tamada Y, Hiwatashi Y, et al. 2013. KNOX2 genes regulate the haploid-to-diploid morphological transition in land plants. Science 339(6123):1067-70

125. Schuster M, Kahmann R. 2019. CRISPR-Cas9 genome editing approaches in filamentous fungi and oomycetes. Fungal Genet. Biol. 130:43-53

126. Shan T, Pang S, Li J, Li X, Su L. 2015. Construction of a high-density genetic map and mapping of a sex-linked locus for the brown alga Undaria pinnatifida (Phaeophyceae) based on large scale marker development by specific length amplified fragment (SLAF) sequencing. BMC Genom. 16:902

127. Song M, Duc Pham HD, Seon J, Chul Woo H-C. 2015. Marine brown algae: a conundrum answer for sustainable biofuels production. Renew.able Sustain.able Energy Rev. 50:782-92

128. Strittmatter M, Grenville-Briggs LJ, Breithut L, Van West P, Gachon CMM, Kupper FC. 2016. Infection of the brown alga Ectocarpus siliculosus by the oomycete Eurychasma dicksonii induces oxidative stress and halogen metabolism. Plant Cell Environ. 39(2):259-71

129. Tarver JE, Cormier A, Pinzón N, Taylor RS, Carré W, et al. 2015. microRNAs and the evolution of complex multicellularity: identification of a large, diverse complement of microRNAs in the brown alga Ectocarpus. Nucleic Acids Res. 43(13):6384-98

130. Torode TA, Siméon A, Marcus SE, Jam M, Le Moigne M-A, et al. 2016. Dynamics of cell wall assembly during early embryogenesis in the brown alga Fucus. J. Exp. Bot. 67(21):6089100

131. Tseng CK. 2001. Algal biotechnology industries and research activities in China. J. Appl. Phycol. 13(4):375-80

132. Umen J, Coelho S. 2019. Algal Sex Determination and the Evolution of Anisogamy. Annu. Rev. Microbiol.

133. Umen JG. 2011. Evolution of sex and mating loci: an expanded view from Volvocine algae. Curr. Opin. Microbiol. 14(6):634-41

133a. Umen JG, Coelho SM. 2019. Algal sex determination and the evolution of anisogamy. Annu. Rev. Microbiol. 73:267-91

134. Van Heeckeren WJ, Dorris DR, Struhl K. 1998. The mating-type proteins of fission yeast induce meiosis by directly activating mei3 transcription. Mol. Cell. Biol. 18(12):7317-26 
135. Wade R, Augyte S, Harden M, Nuzhdin S, Yarish C, Alberto F. 2020. Macroalgal germplasm banking for conservation, food security, and industry. PLOS Biol. 18(2):e3000641

136. Wang X, Chen Z, Li Q, Zhang J, Liu S, Duan D. 2018. High-density SNP-based QTL mapping and candidate gene screening for yield-related blade length and width in Saccharina japonica (Laminariales, Phaeophyta). Sci. Rep. 8(1):13591

137. Yang GP, Sun Y, Shi YY, Zhang L, Guo SS, et al. 2009. Construction and characterization of a tentative amplified fragment length polymorphism-simple sequence repeat linkage map of Laminaria (Laminariales, Phaeophyta). J. Phycol. 45:873-78

138. Yao H. 2019. Regulation of gametophyte-to-sporophyte transitions during the life cycle of Ectocarpus. PhD Thesis, Sorbonne Univ.ersité, Paris

139. Cock JM, Collén J. 2015. Independent emergence of complex multicellularity in the brown and red algae. In: Evolutionary transitions to multicellular life (Ruiz-Trillo I, Nedelcu AM, eds), pp 335-361 Advances in Marine Genomics. Springer Verlag.

140. Ye N, Zhang X, Miao M, Fan X, Zheng Y, et al. 2015. Saccharina genomes provide novel insight into kelp biology. Nat. Commun. 6:6986

141. Zhang J, Liu T, Feng R, Liu C, Chi S. 2015. Genetic map construction and quantitative trait locus (QTL) detection of six economic traits using an $\mathrm{F}_{2}$ population of the hybrid from Saccharina longissima and Saccharina japonica. PLOS ONE 10(5):e0128588

142. Zhang J, Liu Y, Yu D, Song H, Cui J, Liu T. 2011. Study on high-temperature-resistant and high-yield Laminaria variety "Rongfu." J. Appl. Phycol. 23(2):165-71

143. Zhang J, Wang X, Yao J, Li Q, Liu F, et al. 2017. Effect of domestication on the genetic diversity and structure of Saccharina japonica populations in China. Sci. Rep. 7(1):421581-11

144. Zhang J, Yao J-T, Sun Z-M, Fu G, Galanin DA, et al. 2015. Phylogeographic data revealed shallow genetic structure in the kelp Saccharina japonica (Laminariales, Phaeophyta). BMC Evol. Biol. 15(1):237

145. Zhang Q-S, Tang X-X, Cong Y-Z, Qu S-C, Luo S-J, Yang G-P. 2007. Breeding of an elite Laminaria variety 90--1 through inter-specific gametophyte crossing. J. Appl. Phycol. 19(4):303-11 